\title{
Isolated Mediastinal Lymphangioma: Prenatal Diagnosis and Thoracoscopic Treatment
}

\author{
Varlet F. ${ }^{1}$, Guye E. ${ }^{1}$, Varlet M. N. ${ }^{2}$, Tronchet M. ${ }^{2}$, Mariat G. ${ }^{3}$, Chene G. ${ }^{2}$ \\ ${ }^{1}$ Departments of Pediatric Surgery, Centre Hospitalier Universitaire, Saint-Etienne, France \\ ${ }^{2}$ Obstetrics and Gynecology, Centre Hospitalier Universitaire, Saint-Etienne, France \\ ${ }^{3}$ Anesthesiology Centre Hospitalier Universitaire, Saint-Etienne, France \\ E-mail: chenegautier@yahoo.fr \\ Received June 12, 2010; accepted July 13, 2010
}

\begin{abstract}
Isolated mediastinal lymphangiomas are uncommon. We report a case of a $14 \times 8 \mathrm{~mm}$ right paracardiac cyst diagnosed at 20 weeks' gestation. The prenatal evol ution was uneventful and a magnetic resonance im aging at 31 weeks showed the limited extension of the cy st in to the anterior mediastinum. At birth, the bab y was asymptomatic, but the size of the lesion increased steadily $(48 \times 29 \mathrm{~mm})$. At 7 months of life, he underwent a thoracoscopic resection of the cy st without intra or postoperative co mplications. Histological exam ination showed a lymphangioma. This case is remarkable for its prenatal diagnosis, the thoracoscopic treat ment and the 8 years of follow-up without recurrence.
\end{abstract}

Keywords: Mediastinal Tumor; Mediastinal Lymphangioma; Thoracoscopic Treatment; Prenatal Diagnosis

\section{Introduction}

Isolated a nterior m ediastinal 1 ymphangiomas (M L) are uncommon, with an occ urrence less than $1 \%$ o f all the lymphangiomas [1], and most of them are asymptomatic during childhood. They can lead to compression of vital structures, eve $n$ life-t hreatening airway com promise. A prenatal diagnosis is now possible, but se veral pathologies can be evocated whe $\mathrm{n}$ a paracardial cystic lesion is discovered. On ce d iagnosed, they should be resected, typically by thoracotomy or median sternotomy. We report a case of ML with pre natal diagnosis and thoracoscopic treatment.

\section{Case Report}

An $8 \mathrm{~m}$ onths old boy presented a $14 \times 8 \mathrm{~mm}$ an echogenic ri ght-sided a nterior $m$ ediastinal cy st, which ha d been di agnosed at 20 week s' gest ation b y ultrasonographic examination (Figure 1) and conf irmed by magnetic res onance im aging (MRI) at 31 wee ks' gest ation (Figure 2). At 34 weeks, the cyst was heterogeneous and measured $27 \times 23 \mathrm{~mm}$ (Figure 3), but no complications were observed during the preg nancy and th e b aby was delivered at 37 weeks, w eighing $2870 \mathrm{~g}$, w ithout respiratory distress. In the first week of life, sonography and MRI showed a $33 \times 26 \mathrm{~mm}$ cyst and it was decided to delay resection for a few months. By 7 months, the cyst had e nlarged to $48 \times 29 \mathrm{~mm}$, wi thout res piratory com plication, and the baby was operated on account of this evolution. In the operating room, the patient was placed in left lateral decubitus position and 4 ports were $n$ ecessary. The cyst was to the right of the thymus, close to the phrenic nerve. The posterior pari etal pleura was opened over the cyst from its lower part and easily dissected off the thymus; the dissection was performed cephalad along the right phrenic nerve and the pedicle was ligated close to $t$ he s uperior vena ca va. Pat hological exam ination showed a typical lymphangioma. The postoperative course was uneventful and no phrenic palsy or pleural effusion was noted. The pat ient remains asy mptomatic 8 y ears after surgical excision, wi thout rec urrence of $\mathrm{t}$ he $1 \mathrm{ym}-$ phangioma.

\section{Discussion}

Lymphangiomas are beni gn ham artomatous $t$ umors of the lymphatic system and less than $1 \%$ of all cystic ly mphangiomas are pu rely m ediastinal in origin [1 ]. Th ey constitute about $3 \%$ of all mediastinal masses in children [2]. A pre natal diagnosis has already been reporte $d$ in 8 cases for a $n$ i solated ML [3-10]. It $m$ ay be $s$ uspected when the sonographic examination shows a si ngle or multilocated paracardiac an terior m ediastinal cystic 


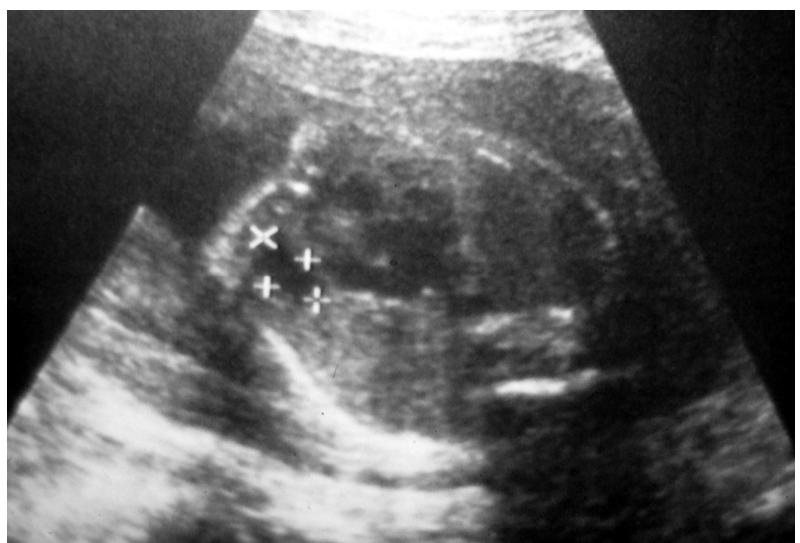

Figure 1. transverse sonography at 20 weeks' gestation showing a $14 \times 8 \mathrm{~mm}$ right paracardiac anechogenic mass.

mass. Som etimes, the lym phangioma was descri bed in the pos- terior mediastinum $[4,10,11]$. In our case, a fetal MRI was also performed and showed the e xact location of the lesion and its ex tension. As the intracystic septations are $\mathrm{n}$ ot alw ays $\mathrm{v}$ isible on fetal $\mathrm{u}$ ltrasonography, other diagnoses ha ve t o b e proposed: pericardial cy st, bronchogenic cyst, thymic cyst, teratom a, esophage al duplication and ne urenteric cyst $[8,12,13]$. A $p$ oor outcome i s pos sible with fetal hy drops a nd hy poplastic lungs, and prenatal thoracocentese may be discussed [3]. For the 8 cas es with prenatal diagnosis, the evoluti on during the pregnancy was var iable with 1 spon taneous disappearance, 3 stable lesions and 4 increases of the ML. Among the 4 last cases, 3 fetal hydrops occurred with 1 neonatal death [3], 1 prematurity at 35 weeks' gestation [7] an $d$ the third underwent dr ainage of the cyst at 24 weeks with success [5]. The ML may be as sociated with a cervical cyst $[9,14]$ and s ometimes with an abdominal extension [15]. A termination of the pregnancy was performed for one fetus pre sented a cervico-mediastinoretroperitoneal lymphangioma [11].

After birth, most ML ar e not d iagnosed because they are asy mptomatic; am ong the patients presenting sy mptoms, the most common are respiratory, cough or stridor by extri nsic com pression of the airway a $\mathrm{s}$ a result of hemorrhage or in flammation, so metimes with acu te respiratory distress $[15,16]$. Le ss c ommon sym ptoms are dysphagia, s uperior vena ca va syndrome, dy sarythmia, Horner's syndrome or phrenic nerve paresis [17]; a fatal outcome in a 12 y ear-old boy has bee $n$ de scribed [18]. Chest radiograph may show an anterior mediastinal mass and sonography may establish its cystic aspect with se ptations; h owever c omputerized t omography an $\mathrm{d}$ es pecially MRI are useful for the diagnosis and the exte nsion of the lesion [14-16]. Calcifications have been described in ML, alth ough this is more characteristic of terato mas [19].

Mediastinal lymphangiomas, as ot her mediastinal masses, must be removed to avoid complications. Among the

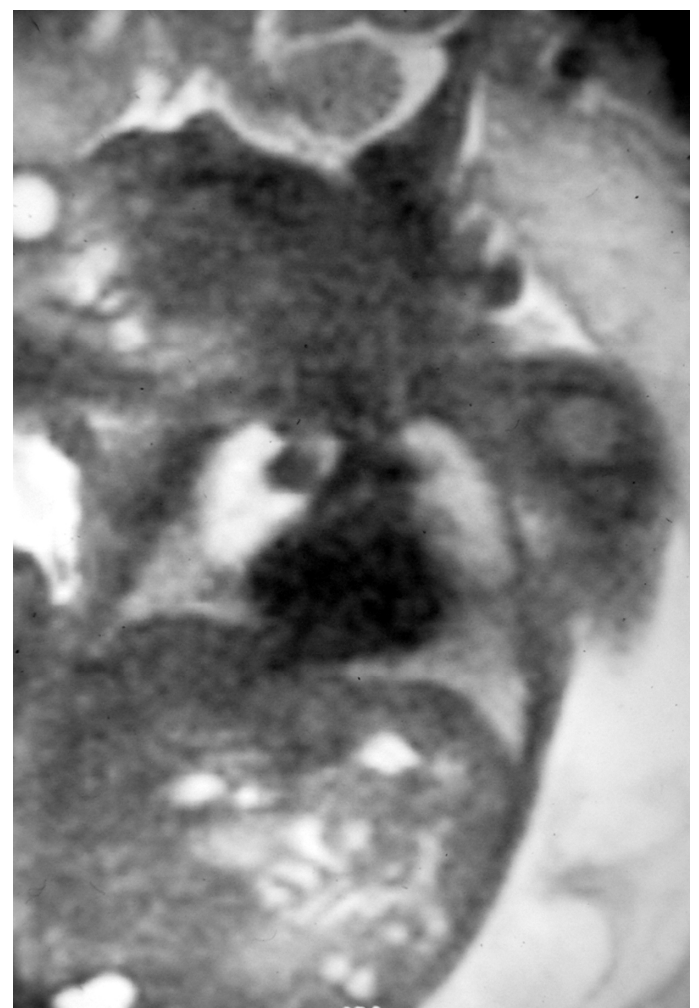

(a)

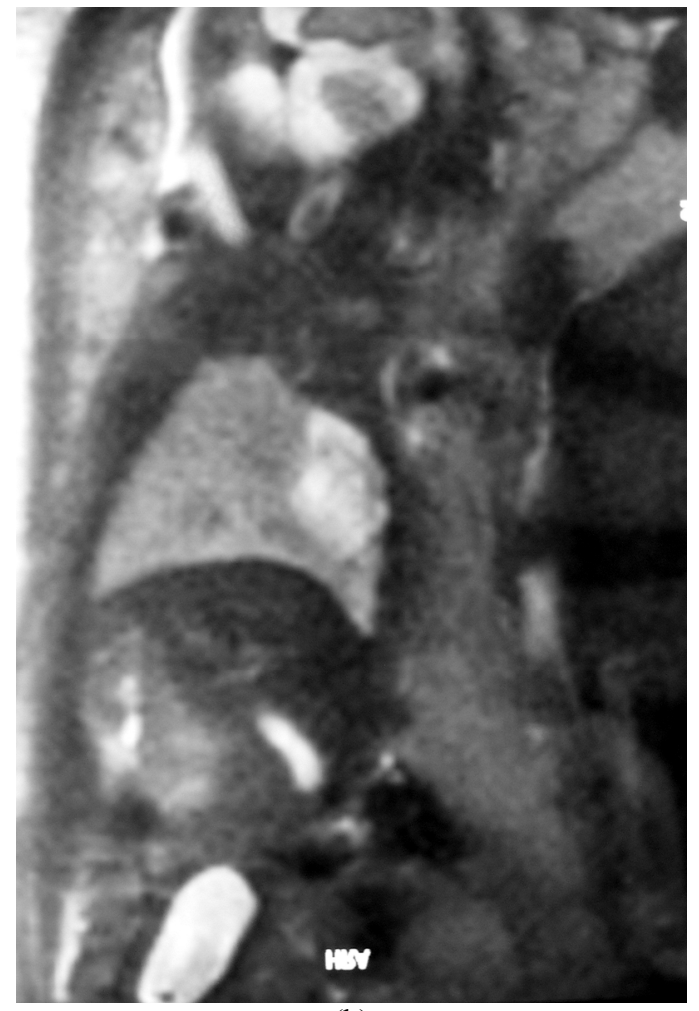

(b)

Figure 2. (a) fetal MRI at 31 weeks with the right mediastinal cyst. Coronal view; (b) fetal MRI at 31 weeks with the right mediastinal cyst. Sagittal view. 


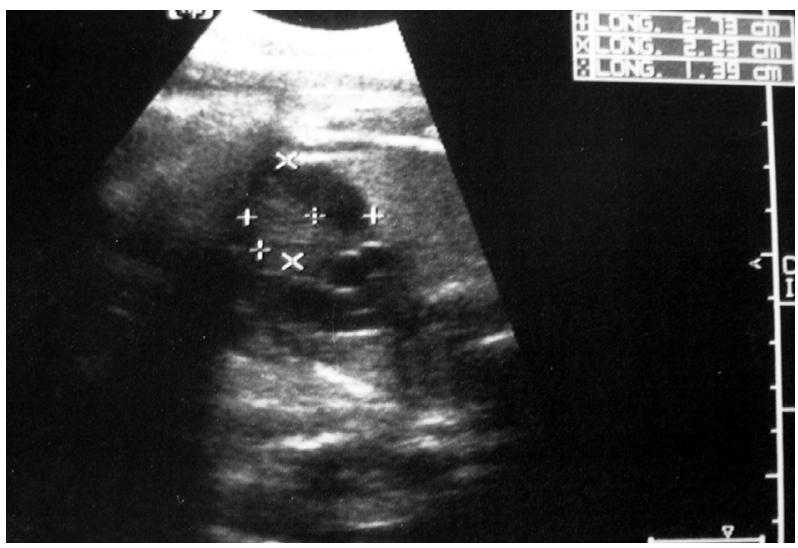

Figure 3. Sonography at 34 weeks' gestation with a $27 \times 23$ $\mathrm{mm}$ heterogeneous right anterior mediastinal cyst.

children with a prenatal diagnosis, 3 thora cotomies were performed at birth for $\mathrm{t}$ he 2 fet al hy drops and 1 huge lymphangioma; one of them underwent a secon d thoracotomy at 19 months for recurrence [5]. One $51 \times 24 \mathrm{~mm}$ ML at 31 weeks' gestation disappeared spontaneously at 6 months of life [6]. The 1 ast $3 \mathrm{ML}$ were respected and overseen after birth, but the ML increased, as in our case, and a thoracot omy was decided at 6 wee ks of life for 2 and 19 months for one. Usually, thoracotomy or median sternotomy are perform ed, but the $t$ horacoscopic treatment of s uch lesion is now possible $[13,20]$; this procedure has been shown to be safe in a s eries of 22 mediastinal cysts in ch ildren, one of which being a ML [13 ], and in 2 other cases at 19 months and 7 years old $[8,16]$. Our c hild was $7 \mathrm{~m}$ onths o ld $\mathrm{w}$ hen $\mathrm{t}$ he $\mathrm{t}$ horacoscopic treatment was pe rformed. Nevertheless, postoperative complications can a rise afte $r$ th e treatm ent of ML; th e surgical resect ion $m$ ay be incom plete because of a dhesions with the great ve ssels or pericardium and rec urrences are po ssible [1,5,9,21]; a few $p$ atients displayed temporary or definitive phren ic nerve palsy or Horn er's syndrome as well $[1,21,22]$. In our case, a complete resection was performed an $d$ the $p$ hrenic ne rve was see $n$ during the entire procedure, without po stoperative complication. We have 8 years of follow-up and we can consider that the recovery is obtained now.

\section{Conclusions}

Isolated m ediastinal 1 ymphangiomas must be $\mathrm{s}$ uspected when a cystic mass is no ted on prenatal son ography in the anterior mediastinum, differential diagnosis including especially pericardial cyst or thymic cyst. The evolution is variable from the spon taneous disappearance to fetal hydrops or life-threatening complications. A t horacoscopic approach is now possible, even in infant.

Author Disclosure Statement: there is no conflict of interest for each author.

\section{References}

[1] C. C. Wrigh t, D. M. Coh en, R. K. Vegunta, J. T. Davis and D. R. King, "Intrathoracic Cystic Hygroma: A Report of Thre e Cases," Journal of Pediatric Surgery, Vol. 31, No. 10, 1996, pp. 1430-1432.

[2] A. I. Philippar t and D. L. F armer, "Benign M ediastinal Cysts and Tumors," In: J. A. O’Neill, M. I. Rowe, J. L. Grosfeld, E. W. Fonkalsrud and A. G. Coran, Eds. Pediatric Surgery, 5th Edition, St. Louis, 1998, pp. 839-851.

[3] A. Lindinger, R. Boos, K. Pist orius, H. G. Limbach, H. J. Jesberger and W. Hoffm ann, "Mediastinal C ystic L ymphangioma as a Cause of Hydrops Fetalis," Klin Pediatr, Vol. 204, No. 2, 1992, pp. 118-122.

[4] Y. Z alel, E. Sh alev, M. Ben-A mi, G. Mogilne r and E. Weiner, "Ultrasonic Diagnosis of Mediastinal Cystic Hygroma," Prenatal Diagnosis, Vol. 12 , No. 3, 1 992, pp. 541-544.

[5] J. K. Muraskas, J. G. Gia nopoulos, A. Husain and P. R . Black, "Mediastinal C ystic H ygroma: P renatal DecomPression with $\mathrm{N}$ eonatal R esection and R ecurrence at 19 Months of Age," Journal of Perinatology, Vol. 13, 1993, pp. 381-384.

[6] M. P. Wu, R. C. Wu, J. S. Lee, W. J. Yao and P. L. Kuo, "Spontaneous Resolution of Fetal Med iastinal C ystic Hygroma," International Journal of Gynecology \& Obstetrics, Vol. 48, No. 3, 1995, pp. 295-298.

[7] E. Jung, H. S. Won, P. R. Lee, I. S. Lee, A. Kim and J. H. Nam, "The Pro gression of Mediastinal Ly mphangiomas in Utero," Ultrasound in Obstetrics and Gynecology, Vol. 16, No. 7, 2000, pp. 663-666.

[8] A. Bernasconi, S. J. Yoo, F. Golding, J. C. Lang er and E. T. Jaeggi, "Etiology and Outcome of Prenatally Detected Paracardial Cystic Lesions: A Case Series and Review of the Literature," Ultrasound in Obstetrics and Gynecology, Vol. 29, No. 4, 2007, pp. 388-394.

[9] C. H. Comstock, W. Lee, R. A. Bronsteen, I. Vettraino and D. We chter, "Fet al Me diastinal Ly mphangiomas," Journal of Ultrasound in Medicine, Vol. 27, No. 1, 2008, pp. 145-148.

[10] R. Ruano, E. Takashi, R. Sc hultz and M. Zugaib, "Prenatal Diagnosis of Posterior Mediastinal Lymphangioma by Two- and Three-Dimensional Ultrasonograph y," Ultrasound in Obstetrics and Gynecology, Vol. 31 , No. 6, 2008, pp. 697-700.

[11] P. L. Giacalone, P. Boulot, P. Deschamps, et al., "Prenatal Diagnosis of a Multifoc al Ly mphangioma," Prenatal Diagnosis, Vol. 13, No. 12, 1993, pp. 1133-1137.

[12] M. Hendrickson, K . Azarow, S . Ein, B . Shand ling, P. Thorner and A. Daneman, "Congenital Thymic Cysts in Children-Mostly Misdiagnosed," Journal of Pediatric Surgery, Vol. 33, No. 6, 1998, pp. 821-825.

[13] J. L. Mic hel, Y . Re villon, P. Montupet, F. Sa uvat, S. Sarnacki, N. Say egh and C. Nihoul-Fekete, "Thoracoscopic Tre atment of Medi astinal C ysts in C hildren," Journal of Pediatric Surgery, Vol. 33, No. 12, 1998, pp. 1745-1748. 
[14] N. Bor ecky, F. Gudinch et, R. Laurini, B. Duv oisin, J. Hohlfeld and P. Schnyder, "Imaging of Cervico-Thoracic Lymphangiomas in Children," Pediatric Radiology, Vol. 25, No. 2, 1995, pp. 127-130.

[15] L. Ghedira, S. Haddad, K. Lajmi, et al., "Isolated Mediastinal C ystic Lymphangioma in Children : About Two Cases." Respiratory Medicine CME, Vol. 1, No. 4, 2008 , pp. 270-273.

[16] A. M. Kavunkal, J. Ramkumar, S. Gangahanumaiah, K. N. Parimelazhag an and V. K. C herian, (2007) "Isolated Mediastinal C ystic Lymphangioma in a Ch ild," The Journal of Thoracic and Cardiovascular Surgery, V ol. 134, No. 6, pp. pp. 1596-1597.

[17] D. K. Robie, M. H. Gurso y and W. J. Pokorn y, "Mediastinal Tum ors-Airway Obstruction and Management," Seminars in Pediatric Surgery, Vol. 3, No. 4 , 1994, pp. 259-266.

[18] A. Adil and M . Ksiy er, "Unu sual Mediastinal C ystic
Lymphangioma. Report of a Case and Review of the Literature," Interventional Radiology, Vol. 39 , 1996, pp. 249-252.

[19] L. E. Swischuk, J. C . Hoeffel and S. D. John, "Primary Intrathoracic Ly mphangioma Masquerading as Teratoma," Pediatric Radiology, Vol. 26 , No. 11, 1 996, pp. 827-829.

[20] S. S. Rothenberg, "Thoracoscopy in Infants and Children: The State of the Art," Journal of Pediatric Surgery, Vol. 40, No. 2, 2005, pp. 303-306.

[21] G. Lem oine an d P. Montupe t, " Mediastinal Tumors in Infancy and Ch ildhood. In Cur rent Topics in General Thoracic Surgery," Elsevier Science Publishing, 1991, pp. 258-272.

[22] H. Takamatsu, H. Noguchi, H. Tahara, H. Kajiy a and H. Akiyama, "Giant Med iastinal Ly mphangioma in a Neonate: Report of a Case," Surgery Today, Vol. 26, No. 7, 1996, pp. 527-531. 